\title{
由陶瓷看中国文化对西方洛可可艺术的影响
}

\section{A BRIEF ANALYSIS OF THE INFLUENCE OF CHINESE CULTURE CERAMIC ON ROCOCO ART OF THE WEST}

\author{
Temmy \\ Chinese Department, Faculty of Humanities, BINUS University \\ Jln. Kemanggisan Ilir III No. 45, Kemanggisan - Palmerah, Jakarta 11480 \\ temmy@binus.edu
}

内容提要

中国文化中, 最早被西方人所接纳的, 应属物质文化之列的丝绸和陶瓷。中国的丝绸最早在古希腊, 罗马时代已传达到西方, 中国在西方人眼中成了 “丝绸之国”。而中国的陶瓷在西方出现较晚。到宋代, 西方才接受中国的陶瓷, 但很快引起了西方人的另一番惊奇, 又把中国称作 “瓷器之国”。瓷器作为一种 文化, 既是物质的, 也是精神的。在欧洲人最先倾倒于瓷器的物质因素后, 也逐渐被它的精神内容所折 服。瓷器的细淢, 精巧, 温润慢慢成为一种被广泛认同的美学风格, 加上其他因素的推波助澜, 形成了 欧洲盛极一时的洛可可风格。本文以参考文献的核查方法进行了分析，并总结了以下 3 个方面: 即 1.中 国陶瓷艺术对西方洛可可艺术的影响 2.对洛可可艺术的评价 3.中国瓷器得以影响洛可可风格的契机来试 者阐述中国审美文化对西方世界的意义所在。

关键词：中国文化中，艺术，陶瓷，洛可可风格的

\begin{abstract}
Chinese culture elements accepted for the first time by the Western countries was ceramic and silk. China's silk was found in ancient Greece during the Roman era and since then China has become the "Country of Silk". Chinese ceramics came to the West a bit later. It was during the Song Dynasty that Western countries started accepting Chinese ceramics, and soon after that Chinese Ceramics had became a new surprise to the Western Countries and had China known as the "Country of Porcelain". Porcelain as a cultural element is considered not only as material but also as a spirit. When the Europeans came to know the porcelain material, they had gradually been influenced by its spiritual content. Delicateness of ceramic slowly became a widely accepted aesthetic style, added with other factors that shaped the formation of the Rococo style that became very popular in Europe. This article used desk study to analyze and summarize the following three aspects: first, the impact of Chinese ceramic art on Western Rococo art, second, the art appreciation of Rococo art and third, to elaborate the influence of Chinese Ceramic and aesthetic in Western Countries.
\end{abstract}

Keywords: Chinese culture, art, ceramics, Rococo style 


\section{内容}

\section{中国陶瓷艺术对西方洛可可艺术的影响}

洛可可艺术在百家争鸣、思想活跃的 18 世纪, 是凭借什么而高标独秀、脱颖而出的呢? 一一原因正在于这种中国味的形式里深藏着的东方美学精神打破了当时西方艺术理念的沉寂, 从而树立起了一个抽象曲线中的异国情调。中国陶瓷艺术对西方洛可可艺术的影响可以从审美 文化与实用价值两大方面来加以考察。

首先, 中国陶瓷所包含的审美文化对当时欧洲审美观念的冲击是巨大的, 极大地推动了洛 可可风格的形成。因为中国陶瓷审美文化中包括的形式美和思想美学都是欧洲社会所不曾有过 的，不得不令他们在惊讶之余感到极大的震撼。

中国陶瓷艺术的形式美主要表现在材质的独特性, 丰富的画面装饰和造型上。第 1 点是材 质的独特性。一方面, 由于瓷土的独特性, 瓷器总显得轻巧精致, 而配以光洁莹润的器面, 其 整体的质面就显出一种水中花、镜中月的飘渺朦胧之美, 给现世的人带来一种虚幻感, 从而营 造出一个梦境般的世界。欧美人直到 18 世纪才真正拥有自己的瓷器。在此之前, 他们从来没有 拥有质地如此精莹细㖑的瓷器。这种独特的美感大大激发了艺术家丰富的想象力, 这也正是中 国陶瓷能在欧美市场独领风骚的重要原因。另一方面, 陶土天然, 加以精巧的工艺及单纯朴素 的造型, 让人的心灵陶醉带来一种人性的享受。这种材质的独特性很好地体现了中国形式美学 的气韵之美, 同时也恰好体现了自然美和艺术美的相互融合。自然与艺术的关系一直是西方艺 术家关注的焦点之一, 中国的陶瓷艺术像其他中国艺术一样, 暗示着解决这种盾的可能性, 这 种中国式的艺术思维给西方艺术家开拓了艺术领域的空间。

第 2 点是丰富的画面装饰。陶瓷的装饰图案丰富多彩, 题材广泛, 人物、山水、花鸟应有 尽有, 手法多样, 有国画风格、工笔风格等。首先中国陶瓷的色彩注重不着痕迹的天然美, 不 事过多堆饰, 有着 “天然去雕饰” 的品位, 即中国美学精神的 “妙造自然”, 体现出一种动感十 足的生命力, 传达了对社会人生无比热爱的精神。其次, 中国陶瓷上的纹样装饰也是反映中国 美学思想的主要表现之一。其中植物性的浴卷形图案以及动物如龙虎图案的曲线式装饰直接影 响西欧的洛可可风格。可以想象, 这些绘有中国风格图案的陶瓷输往西方市场, 中国式的图案 装饰一定使注重立体感，实景感的西方人震惊不已，最终导致了洛可可风格的出现。

此外，第 3 点是造型。陶瓷的造型是由点、线、面组成的空间构架。在中国艺术里，空间 意识有别于西方艺术, 融入了时间的意象, 打破了时间的限制: 西方艺术总体而言讲究透视法, 在平面上绘出逼真的空间, 是艺术与科学结合的空间。而中国艺术讲究境界, 艺术意象立在 “六 合之表”，落在 “四时之外”。中国陶瓷的艺术造型传达的是中国文化中的宇宙精神观。它注重 点、线、面的完美融合, 营造一个神思飞扬, 上天如地的境界, 时间与空间相互存在, 汇聚成 形而上的精神感受。

从上可知, 中国陶瓷的形式美之所以能够对洛可可艺术产生如此大的影响, 是因为中国陶 瓷注重形式与内容的并重发展。西方的传统向来注意具象艺术思维, 而中国陶瓷从本质上说是 
一种抽象性的艺术。当它传入西方时, 观众面对新的抽象思维冲击时, 他们的茫然可想而知。 中国陶瓷把客观形式中抽象生命伸展到最强的限度, 并极力清除了强加于人的物质美, 这就使 观众能直接进入它的艺术的精神境界, 与此发生内在共鸣。中国陶瓷在画面设计、造型等方面 已简约到接近点、线、面的抽象形式，而这种近乎纯抽象的艺术进入当时以具象艺术为主的欧 洲, 必定会产生强烈的碰撞。这种形式上的视觉冲击和艺术思维上的强烈碰撞产生了新的观点, 向当时盛行的艺术样式展开了无形的挑战，其最终结果导致了艺术风格的变动。

依附于陶瓷的形式美而一起呈现在欧洲社会的是中国陶瓷艺术的思想美学。不论是造型、 质地、还是画面装饰都吸收了中国文化中最根本的精神食粮, 那就是儒家的 “礼”, 道家的 “重 已役物”, 以及释家的人生妙悟。儒家因 “克己复礼为仁” 而崇尚 “礼”, 所以审美标准必定以 “礼” 为准则, 以 “仁” 为思想指导。表现在工艺器物的设计造型上, 通常采用既节制又务实 的形式。当然, 这种实用性闪耀着浓厚的人文精神。因为儒家以礼求仁, 延伸其意义, 即以人 为主体而存在。中国陶瓷吸收了这种美学思想, 使陶瓷具有了实用性的世俗美, 同时由于人性 的光环映照, 使得中国陶瓷情致盎然, 内涵丰富。而道家强调 “无为而无不为”, 作为最高理念 的 “道” 是道家所追求的最高境界。因而, “技近乎道 “是道家对技艺的思想要求, 工艺创造只 有到了浑然天成, 丝毫不着痕迹的境地才算 “大巧若拙”。所以中国陶瓷在其造型与瓷面的色调、 构图等配合得和谐统一, 合而不露, 力求一种艺术的自然美, 具有有限中透出无限的意境美。 最后, 释家的思想精神则又给中国陶瓷艺术注入了另一特色一一空灵精微, 典雅幽远的境地。 释家追寻生命的永恒性, 有限中求无限, 瞬间中求永恒, 强调空幻、短暂、寂灭, 中国陶瓷既 有镜中花，水中月的空幻美，同时也又充满了现实生活的生命精神。

总之, 中国陶瓷艺术是在儒释道三教合一的美学思想下产生, 又从日用经验过程中超脱而 出, 以人为主体, 以艺术的方式传达出生命精神的境界, 成为传达生命的载体。所以这种内外 结构兼具的艺术一旦被关注, 必定在某种程度上影响到历史中的一个文化进程, 洛可可艺术的 产生最能说明这个问题。

艺术上的变化必然影响到了外在实用的生活。接受了以陶瓷为代表的中国文化影响而产生 的洛可可运动必然对欧洲社会的生活产生了很大的影响，掀起了一股 “中国热”。

首先, 中国瓷器对欧洲宫廷生活及其建筑装饰产生了巨大影响。几乎每个欧洲国家的帝王、 王后都搜集、收藏中国此气的精品, 并且作为王室的财产。世界上搜集中国陶瓷最多的帝王就 是法国的路易十四、路易十五和萨古森王国的奥古斯特斯。路易十四在凡尔赛宫内修建了托里 阿诺宫, 宫内陈列的大量中国青花瓷器和以蓝、白为基调的宫殿建筑风格相协调, 被称为是 “瓷 器的托里阿诺宫”。路易十五的宠姬旁怕多夫人则动用大量国库的资金来收藏中国的瓷器。当时 在欧洲社会，搜集并鉴赏中国瓷器已成为上层社会的时髦之举。

同时, 对于广大的欧洲市民来说, 中国瓷器的到来, 也是一件好事, 因为这样一来, 中国 精致优美的瓷器代替了原本厨房里和餐桌上昂贵的金银餐具和既粗笨又不干净的陶器餐具。而 且在 18 世纪和 19 世纪初, 欧洲上层社会的家庭内, 还用中国的瓷管来装置下水管道, 甚至连 浴室里的浴缸、水壸、水罐等也都用中国瓷器。对于欧洲市民来说, 中国瓷器不仅给予他们以 东方艺术的享受，而且还带来了清洁、舒适、愉快和便利。

更值得重视的是, 随着中国对欧洲的陶瓷贸易不断扩大, 引起了西方陶瓷艺术家的兴趣, 
刺激和推动了欧洲仿效华瓷, 建立自己的制瓷业。在欧洲, 具有生产玻璃传统的意大利在十五 世纪就已经产生了仿效中国瓷器的陶器，1709 年欧洲正式制造成功真正的硬瓷。这是中国陶瓷 在世界工艺美术发展史上的一个伟大的贡献。

由此可见, 中国陶瓷并不是通过直接性的宣传与著述, 而是以一种活生生的有形的实物参 与了法国文化意识的转变, 以非常微妙曲折的方式改变着其社会意识。中国陶瓷就是以这种艺 术所固有的功能性影响着当时欧洲的社会生活。

\section{对洛可可艺术的正确评价}

洛可可风格被大多数艺术史家贬为肤浅浮华的毫无内容的艺术。正如英国学者赫得逊所说 “洛可可式艺术风格制造了一个凭空想象且充满甜蜜但肤浅的中国”, 洛可可时代通常被认为是 个轻松愉快平用的时期。这样的批评如果深究, 就可以看出背后更深层面的文化理解的问题: 由于中国陶瓷艺术的视觉隐喻物化在最抽象的线条、色彩、造型等基本要素中。因此它要求观 赏者以心灵的方式直接进入艺术本体来活的价值的认同, 这需要内省的方法。由此可见, 这种 艺术一旦进入西方艺术领域, 西方艺术家如果没有进行形而上的严肃思考, 如果没有领会抽象 中的意味, 那么他们从陶瓷艺术中吸收的内容必然流于表面, 也正因为如此, 洛可可的艺术世 界经常被认为毫无深刻内涵可言。这一点也是可以理解的: 洛可可风格源于中国艺术, 而中国 艺术蕴涵有深厚的东方文化，这种文化内涵如果没有被体会到，便会觉得中国艺术中似乎没有 内涵, 一旦被体会到了, 便会被它的博大精深所折服, 但难就难在中国艺术中的文化内涵表面 看好像在形式方面，但实际上需要更多地挖掘形式背后的内在精神。

而且, 客观地看, 由于东西方思维方式的差异以及东西方文化相互理解的偏差, 中国哲学、 艺术的独特性虽然使欧洲人以洛可可的方式来理解与模仿中国的文化，但尽管它采取了中国式 的装饰艺术, 可实际上当时欧洲并没有真正地吸收到中国文化中的精髓, 只是浮光掠影地倾取 了中国艺术中的表面部分，因此也使得洛可可风格的美学思想显得人文精神上的不足，从而朝 着形式的方向发展到极端并显露出很大的片面性也就成为必然。

但同时, 我们也必须承认, 洛可可风格并没有纯粹地流于肤浅, 它蕴涵着可以追寻的内容。 洛可可风格尽管在外观上显得浮华浅显, 然而, 通过历史的纵向比较, 它正暗示了人类社会发 展中最关键的部分一一即人性的自我觉醒。实际上它是充满人性意识的艺术。另一些学者认识 到了这一点, 认为洛可可时期体现了人类文明史发展以来的高峰, 是开始注重人性的时代, 并 非如有些人所认为的那种矫揉造作的表现艺术。如美国学者查尔斯麦克迪说: “洛可可式常常与 18 世纪的颓废混为一谈, 其实那是一种充实和完整的艺术风格。” 洛可可时代的总体艺术特征 传达了 18 世纪的时代精神, 即一种挣脱束缚, 追求生活艺术的人生观念。房龙评价洛可可时代 说: “我认为, 我们的历史学家, 对待洛可可艺术风格, 从来都是不公允。洛可可时期, 绝非象 征轻浮、愚蚌、浮华、浪漫的时期, 而是人类历史在各方面最文明的时代, 这一点我是深信不 疑。利奇温在《十八世纪中国与欧洲文化中的接触》里提到, 洛可可时代的欧洲人对于中国的 认识, 不是通过文字, 而是由于那些浅色的瓷器, 色彩飘逸的闪光丝绸, 向他们展现了梦棩以 求的美好生活的前景”。正是由于中国陶瓷所潜藏的美学精神影响了洛可可风格, 这种美学精神 充满着人文意识, 从而使得洛可可风格显示出对现世人生的积极追求, 以及对日常生活的深切 关注。 
洛可可风格显示了人类追求人性愉悦的意识，他创造了 “一个想象中的光明、空想、精致、 涃雅和欢乐与自由的世界。这种境界充分体现了人类摆脱世俗社会的束缚, 试图进入受过文明 过滤后的理想的自由王国的愿望。这是人类在追求解放自身的过程中的一种浪漫的表达方式。 洛可可风格艺术所显示的人性美是不言而喻的, 它的艺术精神是文艺复兴市人文主义精神的延 伸。就艺术本身而言, 它是艺术发展史上不可或缺的重要阶段, 就其反应的内容而言, 他对后 来的浪漫主义及人性价值的探寻起着奠基的作用。我们决不能因为它有缺陷就全盘否决洛可可 艺术在历史上曾有过的重要意义。

\section{中国陶瓷艺术影响洛可可艺术的契机}

有一个问题值得我们思考: 为何中国陶瓷有如此大的力量能为西方社会所接受并成为洛可 可风格的主诱力量之一? 应该说, 这和当时社会思想背景是分不开的：中国的陶瓷能进入西欧 并且由此而掀起一场艺术演变运动, 其主旨就在于华夏美学精神所蕴含的人文精神, 而这种哲 学意味正好契合了当时 17-18 世纪西欧的社会思潮一一哲学思潮的形而上要求。

在洛可可风格之前的巴洛克风格是 17 世纪欧洲主要的艺术风格。巴洛克风格最初发展于罗 马, 所以它力图复活古帝国的庄严、宏伟和富丽堂皇。它是一种骄傲及力量的艺术, 它以宏伟 和华丽为目的。虽然它本身常常允许大量富于幻想的装饰, 但其主要特点是雄浑, 很能适应于 太阳王一一法国国王路易十四的尊严和壮丽。这时期的新古典主义讲求自然、理性、真实、转 向学习古典来表现永恒, 但其实更多地展示了封建宫廷理想的文艺理念。而当时新兴资产阶级 已处于上升时期，人类自我意识不断增强，但 “人” 的意识已苏醒。到了 18 世纪，启蒙时代到 来, 启蒙的形而上思考及其人文主义精神必然对宗教及专制信仰起到破坏作用, 宗教反改革运 动和新专政制度, 都已经失去了它们俘获人们的能力。法国君主政体已剥夺了贵族的政治力量, 迫使他们依附于君主自己, 然而这个君主非但没能成为欧洲的盟主, 灾祸却接连而来, 以光荣 革命开始的路易十四王权统治竟以悲惨的结局而告终。皇家伟大的肥皇泡破坏了, 法国贵族社 会虽仍有特权, 但在政治上却是无力的, 他们孤立于人民, 对教堂和国家感到幻灭, 他们就带 着这一切而沉湎于一种优美的文化艺术之中，并被欧洲人尊之为高雅生活典范。这是一个宗教 怀疑主义与幻灭的时代, 这个时代的思想意识已经超越了巴洛克时代, 巴洛克时代象征帝国与 天国风范的雄浑艺术再也不适应这给进一步转向人自身的时代。它那浑厚的庄严显得愚蚌而令 人厌烦, 它那铺张华丽再也不能感动人。此时的人们需要用艺术一一一种尽可能小的宏伟的风 格来为自己制造一个新世界——个想象中的光明、空想、精致、涃雅和欢乐自由的世界。

而也就在这个思想动荡不安时刻, 那些耶稣会的传教士们待会了来自遥远东方的文化, 其 中就有陶瓷。一位西方学者说过: “洛可可艺术风格和古代中国文化的契合, 其全部秘密就在于 瓷片所体现出来的纤细入微的情调”。瓷器那种光洁莹润的质感, 流畅写意的线条, 中国式绘画 图案都大大刺激了西方艺术家的创作灵感, 使他们感受到了一种与中世纪呆板严肃模式完全不 同类型的艺术风格, 引得西方艺术家纷纷模仿中国风格。后来随着中国陶瓷在西方的销路和受 欢迎程度的不断增长, 也刺激和推动了欧洲仿效中国瓷器建立自己的制瓷业。对中国瓷器的仿 制是洛可可风格运动的一个主要内容, 虽然西方并没有能够完全领会到东方艺术的精华而只是 撷取了其装饰性的表面部分, 但欧美艺术家从防治中国此气的过程中得到了更大的艺术风格改 变的动力, 这一点是不容忽视的。他们只有亲身研究中国瓷器的物理、化学制作过程及艺术构 思过程, 才能够创造出真正属于欧美风格的瓷器, 并自此以后, 步向独立, 趋于成熟, 完成了 美学理念的变迁。 


\section{结语}

所以, 综上所述, 陶瓷所代表的中国文化之所以能够为欧洲所接受并掀起洛可可运动, 关 键原因有 2 点。一是陶瓷所蕴含的中国文化本身就具有内在的价值, 对人类社会有贡献。中国 五千年的文化源远流长, 博大精深, 在 18 世纪出于世界领先之列。但更重要的原是在于, 中国 文化之所以会被西方接受, 正在于它适应了西方历史发展的需要。可以看出, 虽然中国艺术对 于洛可可风格的形成与发展起了很大的推动作用。但并不是洛可可的中国特征就可以认为是整 个中国艺术的代表。洛可可的设计家们从中国倾取的, 只是投合他们趣味的东西, 而这仅仅是 中国传统的一个方面, 大部分唐宋时代的艺术, 他们即便认识到也不会欣赏。他们对于中国艺 术天才所擅长的宏伟和庄严, 无动于衷。他们仅仅只是寻求他那离奇和典雅的风格的精华。他 们认识到的并不是真正的中国, 而是他们创造了一个自己幻想中的中国, 一个全属臆造的出产 丝、瓷和漆的仙境, 既精致又虚无飘渺, 赋给中国艺术的主题以一种新颖的幻想的价值, 这正 是因为他们对此一无所知。史景迁教授在《文化类同和文化利用》这本书中曾说过 “制约着西 方的中国形象的, 主要不是中国的现实, 而是西方自身的需要和问题”。例如十七世纪最初 20 年出现了赞扬中国的第一个高潮, 当时正是欧洲处于 30 年战争的前夜, 人们对于现实极度不满, 暴虐横行的年代。而西方对于中国感兴趣的另一个高潮则是在第一次世界大战后, 西方普遍感 到沮丧和绝望, 人们需要创作一个 “他性” 来发泄不满和寄托希望。西方启蒙运动、狂巍运动 的那些诗人、作家、思想家、学者之所以赞赏中国文化, 正是因为它适应了西方社会要求变革 的需要。例如当时法国哲学家的思想与他们对耶稣会传教士带到欧洲的有关中国典章制度的著 作的研究关系密切。以孟德斯鸭的《论法的精神》为例, 其中对于中国典章制度的认识实际上 是其打碎中世纪文明的有力武器。而主张 “全盘中化” 的伏尔泰之所以厚爱中国的原因也是由 于中国当时是反天主教的国家, 而他本人就是一个憎恨天主教的人。现在再回过头来看洛可可 运动, 以中国的陶瓷作为代表的中国美学思想之所以能影响欧洲, 是因为在那个欧洲艺术家茫 然若失急于想改变现有的艺术风格却又不知从何入手的关键时刻, 包括陶瓷在内的中国工艺品 的出现带给了他们很大的冲击, 同时也认识到中国陶瓷所表现出的人性美是对中世纪美学的有 力反击。其实, 不仅法国如此, 其他国家也都是从自身的需求来接受中国文化的。美国建国之 初, 起草《独立宣言》的杰弗逊因追求独立而关注中国人。富兰克林则大量收集有关中国社会 组织形式资料加以研究分析, 为年轻的美国寻找治国方略。德国戏剧家布莱希特之所以对中国 戏剧发生兴趣, 正是因为和他所提倡的 “间离效果” 不谋而合, 可供鉴赏。当代西方生态学关 注中国古典哲学, 也正是想从 “天人合一” 的思想中吸取力量, 追求人与自然的和谐平衡。可 以总结出, 西方文化对中国文化的学习和吸收, 真的可以用葡萄牙人品托提出的一个 “利用中 国” 的概念来概括, 即欧洲人总是有意识地用中国的文化来改进或批判欧洲的文化, 使之不断 改良前进。这一点是值得我们深思的一一在今天, 我们应该以怎样的态度来学习西方的文化?

洛可可艺术是新古典主义与启蒙思想相交杂的产物。一方面, 新古典主义强调形式, 另一 方面，启蒙思想又赋予洛可可艺术以 “人” 的气息，而东方的中国陶瓷艺术大规模输入，中国 美学精神在西方仿制与模仿中国陶瓷过程中, 在艺术家努力汲取灵感的过程中, 已经加入了前 二者的行列, 参与了十八世纪伟大变动, 深入到了洛可可风格的审美核心, 即形而上的审美意 识领域。这也正是中国陶瓷美学精神对西方洛可可艺术的影响真正意义所在。 


\section{参考文献}

赫德逊 王遵仲 李申 张毅 译. (1995). 《欧洲与中国》 (英). 北京.中华书局出版社

朱培初编. (1984).《明清陶瓷和世界文化的交流》北京.轻工业出版社

沈福伟. (1985). 《中西文化交流史》上海.上海人民出版社年

利奇温著 朱杰勤译. (1991). 《十八世纪中国与欧洲文化的接触》（德）北京.商务印书馆

三上次南著 胡德芬译. (1983).《陶瓷之路》 (日) 天津. 天津人民出版社

朱顺龙 李建军编. (2003).《陶瓷与中国文化》北京.汉语大词典出版社

史景迁著 廖世奇 彭小樵译. (1990). 《文化类同与文化利用》（美）北京. 北京大学出版社 